\title{
FORMULASI STRATEGI BERSAING PT. IMAGO KREASI KOMUNIKA DI INDUSTRI JASA PERIKLANAN
}

\author{
Teti Filantri Siregar ${ }^{* 1}$, Heny K Daryanto**), dan Setiadi Djohar***) \\ *) PT. Imago Kreasi Komunika \\ J1. Benda Atas No.36H Jeruk Purut, Cilandak, Jakarta 12560 \\ **) Sekolah Bisnis, Institut Pertanian Bogor \\ Jl. Raya Pajajaran, Bogor 16151 \\ ${ }^{* * *}$ PPM Manajemen \\ Jl. Menteng Raya 9, Jakarta 10340
}

\begin{abstract}
After its establishment, PT. Imago Kreasi Komunika had experienced highly rapid growth from year to year; however, in 2013 the company suffered its losses. This condition was successfully overcome by the company by gaining its profit in 2014. Due to this condition, the company has been worried so that it decided to formulate of appropriate strategies to be able to grow and compete with other advertising companies. This study aimed to evaluate the vision and mission and analyze the internal and external factors of the company to formulate an appropriate strategy formulation for PT. Imago Kreasi Komunika. The research was conducted by case study approach the company. The method of analysis used was to evaluate the company's vision and mission and stakeholder expectations. To analyze the internal factors, the Internal Factor Analysis Summary (IFAS) matrix, External Factor Analysis Summary (EFAS), and Strategy Factor Analysis Summary (SFAS) were used. The research was conducted through non-probability sampling approach with purposive sampling technique by selecting respondents consisting of seven internal experts and three external experts. The results showed that PT. Imago Kreasi Komunika has a Unique Selling Point which is not owned by other advertising companies that is final artwork packaging design. This Unique Selling Point can be the key to develop the company and compete with other advertising companies in Indonesia.
\end{abstract}

Keywords: strategy formulation, advertising company, EFAS, IFAS, SFAS

\begin{abstract}
ABSTRAK
Sejak berdiri PT.Imago Kreasi Komunika mengalami perkembangan sangat pesat dari tahun ke tahun, namun ditahun 2013 perusahaan mengalami kerugian. Kondisi ini berhasil diatasi oleh perusahaan dengan kembali mendapatkan profit di tahun 2014. Keadaan seperti ini mengkhawatirkan perusahaan sehingga perusahaan memutuskan perlunya sebuah formulasi strategi yang tepat untuk dapat berkembang dan bersaing dengan perusahaan iklan lain. Penelitian ini bertujuan mengevaluasi visi dan misi, menganalisis faktor internal dan eksternal perusahaan untuk menyusun sebuah formulasi strategi yang tepat bagi PT.Imago Kreasi Komunika. Penelitian dilakukan dengan pendekatan studi kasus PT.Imago Kreasi Komunika. Metode analisis yang digunakan adalah dengan melakukan evaluasi visi dan misi perusahaan serta harapan-harapan stakeholder. Untuk menganalisis faktor-faktor internal digunakan matriks Internal Factor Analysis Summary (IFAS), External Factor Analysis Summary (EFAS), dan Strategy Factor Analysis Summary (SFAS). Penelitian dilakukan melalui pendekatan non probability sampling dengan teknik purposive sampling dengan memilih responden yang terdiri dari tujuh pakar internal dan tiga pakar eksternal. Hasil penelitian menunjukkan bahwa PT. Imago Kreasi Komunika memiliki Unique Selling Point yang tidak dimiliki oleh perusahaan iklan lain, yaitu final artwork packaging design. Unique Selling Point ini dapat dijadikan kunci untuk mengembangkan perusahaan dan bersaing dengan perusahaan iklan lain di Indonesia.
\end{abstract}

Kata kunci: formulasi strategi, perusahaan iklan, EFAS, IFAS, SFAS

${ }^{1}$ Alamat Korespondensi:
Email: lalasiregar77@gmail.com 


\section{PENDAHULUAN}

Perusahaan jasa merupakan salah satu sektor usaha yang diprediksikan akan berkembang. Diantara perusahaan yang memiliki kesempatan berkembang adalah jasa periklanan. Menurut Nielsen Advertising Information Services (mencakup 14 stasiun TV nasional dan jaringan, 101 surat kabar dan 133 majalah dan tabloid). Semua angka didasarkan pada rate card gross, tanpa menghitung diskon, promo, dll) pertumbuhan belanja iklan di triwulan kedua tahun 2015 tumbuh sebesar $6 \%$, setelah sebelumnya turun $1 \%$ di triwulan pertama. Secara keseluruhan, sepanjang semester pertama 2015 total belanja iklan meningkat sebesar $4 \%$.

PricewaterHouse Coopers ( $\mathrm{PwC}$ ) menganalisis bahwa Indonesia mengalami peningkatan belanja iklan yang tertinggi bila dibandingkan dengan kondisi peningkatan secara global. PwC memprediksi belanja iklan Indonesia dalam Global Entertainment and Media Outlook 2014-2018 bahwa belanja iklan entertainment dan media akan terus meningkat selama periode 20132018 pada compound annual growth rate (CAGR) sebesar $10,1 \%$. Pertumbuhan ini terjadi karena semakin banyak masyarakat kelas menengah dan meningkatnya pendapatan masyarakat di Indonesia. Peningkatan yang berkesinambungan ini akan meningkat dari 10,2 miliar ditahun 2013 menjadi 16,5 miliar tahun 2018. Pertumbuhan belanja iklan selama lima tahun ke depan secara garis besar dipengaruhi oleh iklan digital, diikuti oleh iklan televisi. Namun, iklan di media cetak seperti koran tetap mencatat belanja iklan terbesar di Indonesia. Perkembangan entertainment dan media di Indonesia diperkirakan merupakan perkembangan yang terbesar di Asia Pasifik hingga tahun 2018 mendatang.

Prediksi kondisibisnis yang membaik dan meningkatnya belanja iklan di Indonesia membuka peluang besar bagi berkembangnya perusahaan iklan di Indonesia salah satunya PT. Imago Kreasi Komunika (Imago Communication) sebagai perusahaan Full Service
Agency yang menawarkan jasa desain komunikasi, produksi, hingga media placement. Perusahaan yang masuk ke dalam kategori Small Medium Enterprise (SME) ini berdiri sejak tahun 2002. Mayoritas klien perusahaan adalah perusahaan multinasional di Indonesia.

Imago berkembang pesat dalam kurun waktu 14 tahun dengan penjualan yang terus meningkat setiap tahun. Secara global perusahaan terus mengalami peningkatan setiap tahun semenjak berdiri tahun 2002 sehingga membuka peluang bagi perusahaan untuk mengembangkan usaha. Namun, ditahun 2013 profitabilitas perusahaan mengalami penurunan yang sangat signifikan hingga minus. Penurunan profit ini disebabkan kondisi internal dan eksternal perusahaan yang tidak kondusif sehingga terjadi penurunan beberapa account besar. Kondisi perusahaan di tahun 2013 yang kurang baik mendorong perusahaan untuk mengevaluasistrategi danmengambiltindakan. Mazarol (2009) mengatakan bahwa perusahaan yang memiliki perencanaan secara formal mampu menghadapi perubahan yang terjadi di dalam internal perusahaan. Dan ditemukan juga bahwa adanya hubungan antara sales turnover dengan visi para manajer dan pemilik. De Gregorio (2012) dalam penelitian terhadap perusahaan periklanan di Amerika Serikat mencoba memahami konflik yang sering terjadi di dalam perusahaan periklanan. Hasil penelitian menemukan bahwa konflik destruktif maupun konflik membangun memengaruhi kualitas dan hasil pekerjaan para pekerja iklan. Pada PT.Imago Kreasi Komunika keadaan yang tidak kondusif kemungkinan menjadi salah satu faktor yang menurunkan kualitas dan kuantitas pekerjaan yang menyebabkan penurunan penjualan. Manajerial memiliki implikasi besar terhadap usaha memperbaiki kualitas kerja pada sebuah organisasi (Widodo, 2011). Penurunan signifikan ini terlihat pada Tabel 1 yang menunjukkan rasio profitabiltas perusahaan dari tahun 2010 hingga 2014.

Tabel 1. Rasio Profitabilitas PT.Imago Kreasi Komunika Tahun 2010-2014

\begin{tabular}{llllll}
\hline \multicolumn{1}{c}{ Keterangan } & 2010 & 2011 & 2012 & 2013 & 2014 \\
\hline Profit Margin on Sales (\%) & 35,84 & 17,63 & 17,66 & $-3,07$ & 5,61 \\
Return on Investment (\%) & 53,20 & 27,10 & 20,42 & $-4,03$ & 8,24 \\
Return on Equity (\%) & 54,59 & 29,12 & 23,66 & $-4,81$ & 8,35 \\
Return on Assets (\%) & 42.06 & 20,35 & 16,34 & $-3,18$ & 5,82 \\
Gross Profit Margin (\%) & 75,43 & 59,91 & 69,22 & 47,41 & 56,33 \\
Net Profit Margin (\%) & 28,33 & 13,24 & 14,13 & $-2,42$ & 3,96 \\
\hline
\end{tabular}


Dari Tabel 1 rasio profitabilitas PT.Imago Kreasi Komunika Tahun 2010-2014 secara garis besar profitabilitas perusahaan tidak stabil namun tetap memperoleh profit hingga tahun 2012. Permasalahan mulai terjadi di tahun 2013 dengan meruginya perusahaan. Tahun 2014 perusahaan kembali meraih profit, tetapi sangat kecil. Penurunan profit dan ketidakstabilan kondisi perusahaan menjadi permasalahan yang perlu diatasi segera. Oleh karena itu, perusahaan perlu mulai menata sebuah formulasi strategi agar tidak merugi lagi dan dapat terus meraih profit bahkan berkembang sehingga dapat bersaing dengan perusahaan iklan lain di Indonesia.

Melihat kondisi perusahaan langkah strategis yang tepat harus segera dilakukan melalui sebuah formulasi strategi. Dalam menyelesaikan isu-isu strategis yang muncul, strategi utama sangat berkaitan dengan strategi-strategi pendukung seperti meningkatkan kualitas SDM, memanfaatkan investor, sosialisasi kepada masyarakat, mengoptimalkan keterkaitan visi, misi dan tujuan organisasi, serta meningkatkan kualitas perencanaan dan penganggaran (Zubaidha, 2014). Peran manajemen dan strategi sangat dibutuhkan pada perusahaan seperti ini. Formulasi strategi ini turut membantu bisnis agar dapat bersaing di dunia modern. Perusahaan yang mampu bertahan hidup harus dapat juga memperoleh laba jangka panjang, memperoleh laba sehingga perusahaan akan dapat tumbuh dan berkembang (Tantra, 2015). Melihat permasalahan yang terjadi di PT. Imago Kreasi Komunika maka penelitian ini bertujuan mengevaluasi visi dan misi, menganalisis faktor internal dan eksternal perusahaan untuk menyusun sebuah formulasi strategi yang tepat bagi PT. Imago Kreasi Komunika.

Tabel 2. Jenis dan sumber data

\begin{tabular}{lll}
\hline \multicolumn{1}{c}{ Jenis Data } & \multicolumn{1}{c}{ Teknik Pengambilan Data } & \multicolumn{1}{c}{ Sumber Data } \\
\hline $\begin{array}{l}\text { Data Primer } \\
\text { eksternal perusahaan }\end{array}$ & $\begin{array}{l}\text { Kuesioner, wawancara (in-depth } \\
\text { interview) }\end{array}$ & $\begin{array}{l}\text { Internal perusahaan (Komisaris Utama, Direktur } \\
\text { Utama, Finance Manager, Account Director, Final } \\
\text { Artwork Manager, event Manager) }\end{array}$ \\
$\begin{array}{lll}\text { Gambaran lingkungan eksternal } \\
\text { Data Sekunder }\end{array}$ & $\begin{array}{l}\text { Kuesioner, wawancara (in-depth } \\
\text { interview) }\end{array}$ & $\begin{array}{l}\text { Eksternal perusahaan dari pakar periklanan, } \\
\text { printing dan akademisi }\end{array}$ \\
Analisis konten data sekunder & $\begin{array}{l}\text { Data laporan rugi laba tahun 2010-2014 (PT. } \\
\text { Imago, 2015), Data laporan tahunan perusahaan, } \\
\text { Data website AC Nielson (2015) }\end{array}$ \\
\hline
\end{tabular}

\section{METODE PENELITIAN}

Penelitian dilaksanakan di PT.Imago Kreasi Komunika, Jakarta Selatan. Obyek penelitian adalah PT.Imago Kreasi Komunika dengan waktu penelitian dimulai dari bulan Agustus hingga Desember 2015. Data penelitian yang digunakan terdiri dari data primer dan data sekunder. Pengumpulan data primer dilakukan melalui wawancara mendalam (in-depth interview), kuesioner dan Focus Group Discussion (FGD) kepada pihak internal manajemen perusahaan dan eksternal perusahaan yaitu stakeholder yang terkait dengan perusahaan serta pakar periklanan. Responden pakar dipilih secara sengaja dengan kriteria para praktisi periklanan dan para professional yang memiliki hubungan kerja dengan PT. Imago Kreasi Komunika. Dengan demikian segala bentuk informasi yang diperoleh dapat lebih akurat.Jenis dan sumber data selengkapnya pada Tabel 2 .

Dalam mengolah dan menganalisis data dilakukan beberapa tahapan, yaitu evaluasi visi dan misi perusahaan serta harapan-harapan stakeholders, identifikasi faktor internal dan eksternal melalui observasi di lapangan, wawancara, pemberian kuesioner dan FGD. Pengolahan data dilakukan dengan menyusun lima faktor utama untuk masing-masing faktor yang mempunyai dampak penting (critical success factors) untuk aspek internal (kekuatan dan kelemahan) dan eksternal (peluang dan ancaman) PT.Imago Kreasi Komunika, memberikan bobot dari tiap-tiap faktor menggunakan pairwise comparison, kemudian mengalikan bobot dengan rating untuk memperoleh total skor terbobot bagi perusahaan berbentuk matriks Internal Factor Analysis Summary (IFAS) dan External Factor Analysis Summary (EFAS) yang digabungkan dalam Strategy Factor Analysis Summary (SFAS) untuk memperoleh formulasi strategi PT.Imago Kreasi Komunika. 


\section{HASIL}

Proses formulasi strategi PT.Imago Kreasi Komunika dimulai dari perumusan visi dan misi, harapan-harapan stakeholder, analisis faktor internal, analisis faktor eksternal, serta penetapan strategi yang digunakan.

\section{Evaluasi Visi dan Misi}

Visi adalah sebuah rencana yang diharapkan akan terjadi di masa depan sehingga strategi organisasi harus dapat membaca situasi perusahaan saat ini dan memperkirakan yang akan terjadi di masa mendatang untuk dapat mengambil tindakan yang perlu dilakukan perusahaan. Formulasi strategik merupakan bagian dari perencanaan strategic. Saat melakukan perencanaan strategik yang pertama dianalisis adalah visi dan misi perusahaan apakah masih sesuai atau belum (Powers, 2012). Berdasarkan evaluasi visi dan misi PT.Imago Kreasi Komunika yang ada saat ini masih sesuai harapan, yaitu visi "Become the most reliable brand communication company. A company that is composed of small parts division in synergy to form a large force with the ability to enter global's economic future".

Pernyataan misi merupakan elemen yang sangat penting dalam komunikasi bisnis sebuah organisasi bagi semua stakeholder. Karena terkadang pernyataan misi dapat berubah seiring dengan perubahan lingkungan yang terjadi. Pernyataan misi merupakan komponen yang tidak terlepas dari menyusun sebuah perencanaan strategik (Powers, 2012). King et al. (2010) melihat bahwa beberapa perusahaan menyesuaikan pernyataan misi dengan perubahan lingkungan yang terjadi. Misi suatu perusahaan merupakan tujuan unik yang membedakan sebuah perusahaan dengan perusahaan lain yang sejenis dengan mengidentifikasikan lingkup dari operasinya. Pernyataan misi perusahaan sangat bervariasi bahkan cenderung kompleks dan tidak menggambarkan misi perusahaan yang sebenarnya (Azaddin, 2012). Perusahaan yang berhasil tumbuh bukan karena pemimpinnya yang karismatik, melainkan karena gebrakan ide yang mampu menuangkan pernyataan misi atau menciptakan struktur organisasi yang sempurn (Cocks, 2010). Oleh karena itu, perusahaan harus memberi pernyataan misi yang jelas agar terfokus menjalankan bisnisnya. PT.Imago Kreasi Komunika memiliki misi "We help clients to think that their brand is different from the others. And our duty is to seek out and communicate it, so that the brand always stands out and remembered by the target market."
Berdasarkan pendapat responden, misi perusahaan ini masih sesuai dengan perkembangan zaman dan tidak memerlukan peneyesuaian misi lebih lanjut. Visi dan misi perusahaan yang dicetuskan 13 tahun lalu masih mengikuti perkembangan globalisasi dunia. Ide yang cepat, produk serta pelayanan yang baik bergerak secara eksponensial di seluruh dunia setiap hari. Teknologi memegang peranan terhadap perubahan yang terjadi di seluruh dunia. Untuk dapat terus eksis perusahaan iklan harus terus mengikuti globalisasi dunia Frith (2003). Hingga saat ini PT.Imago mengikuti globalisasi dunia dari sisi perkembangan teknologi hingga update pengetahuan. Inilah yang menjadi salah satu nilai tambah bagi perusahaan.

\section{Harapan-Harapan Stakeholders}

Dalam menyusun formulasi strategi harapan-harapan stakeholder memegang peranan penting untuk memenuhi keinginan stakeholder. Identifikasi harapan stakeholder internal dilakukan melalui wawancara, pengisian kuesioner dan FGD, harapan-harapan stakeholders terbagi menjadi harapan stakeholders internal yang terdiri dari management dan stakeholders eksternal yang terdiri dari klien, pakar periklanan dan supplier untuk memperoleh gambaran yang lebih objektif terhadap harapan mereka kepada PT.Imago Kreasi Komunika. Hasil dari analisis harapan stakeholders secara garis besar pada Tabel 3.

\section{Analisis Faktor Internal}

Evaluasi kekuatan, kelemahan, peluang dan ancaman terhadap PT.Imago Kreasi Komunika dilakukan dengan menggunakan matriks IFAS dan EFAS. Anlisis lingkungan internal dan eksternal digunakan untuk melihat respon manajemen terhadap faktor-faktor yang dianggap penting oleh perusahaan (Wheelen dan Hunger, 2012). Evaluasi dilakukan berdasarkan bobot dan rating untuk mengukur skor bobot tertimbang yang masing-masing berguna untuk menentukan kekuatan, kelemehan, peluang dan ancaman PT.Imago Kreasi Komunika. Penilaian dengan menggunakan bobot dan rating dilakukan melalui kuesioner dan diskusi bersama pihak internal dan eksternal PT.Imago Kreasi Komunika secara mendalam untuk mendapatkan hasil yang lebih tepat dan akurat. Namun, tidak semua perusahaan dapat menggunakan metode ini. Widodo et al. (2008) menggunakan balanced scorecard untuk melakukan penelitiannya. 
Tabel 3. Harapan-harapan stakeholder

\begin{tabular}{|c|c|c|}
\hline Keterangan & Harapan & Strategi perusahaan (memenuhi harapan stakeholders) \\
\hline Produk/usaha & $\begin{array}{l}\text { 1. Memiliki Unique Selling Point (USP) dari } \\
\text { services yang dimiliki oleh PT.Imago Kreasi } \\
\text { Komunika. } \\
\text { 2. Menjadi the best company dalam } \\
\text { menangani kategori desain grafis, event dan } \\
\text { final artwork. }\end{array}$ & $\begin{array}{l}\text { 1. Menambah skill karyawan } \\
\text { 2. Memberi nilai tambah pada setiap proses pekerjaan } \\
\text { 3. Memiliki tim strategi dan marketing yang kuat serta } \\
\text { finansial yang mendukung usaha yang dijalankan. }\end{array}$ \\
\hline Bisnis & $\begin{array}{l}\text { 1. Mengembangkan bisnis unit yang sudah } \\
\text { ada agar lebih baik dalam menghadapi } \\
\text { persaingan } \\
\text { 2. Diversifikasi usaha dalam satu kategori } \\
\text { yang saling memperkuat antarlini usaha }\end{array}$ & $\begin{array}{l}\text { 1. Menambah sarana dan prasarana yang dibutuhkan } \\
\text { sesuai perkembangan bisnis. } \\
\text { 2. Menambah klien dari kategori produk selain Fast } \\
\text { Moving Consumer Goods (FMCG), seperti Banking, } \\
\text { Automotif, Telco, dan lain-lain. }\end{array}$ \\
\hline Klien & $\begin{array}{l}\text { 1. Mempererat hubungan dengan klien yang } \\
\text { sudah ada dengan lebih banyak komunikasi } \\
\text { dua arah. } \\
\text { 2. Menambah jumlah klien }\end{array}$ & $\begin{array}{l}\text { 1. Mengadakan joint workshop untuk menjelaskan } \\
\text { cara kerja dan ketentuan (policy) masing-masing } \\
\text { perusahaan } \\
\text { 2. Menambah exposure perusahan ke luar (bisa dalam } \\
\text { bentuk ikut pameran dan exhibition, atau memuat } \\
\text { iklan di media elektronik) }\end{array}$ \\
\hline Kompetensi & $\begin{array}{l}\text { 3. Menambah kompetensi agar dapat bersaing } \\
\text { dan menambah jenis usaha }\end{array}$ & $\begin{array}{l}\text { 1. Training, workshop dan seminar } \\
\text { 2. Akusisi atau Joint Venture dengan perusahaan } \\
\text { dengan kompetensi yang sesuai }\end{array}$ \\
\hline
\end{tabular}

Perusahaan memiliki lingkungan internal masingmasing yang nantinya akan memunculkan kelemahan dan kekuatan dari perusahaan (Yulianti, 2014). Analisis lingkungan internal menyediakan informasi yang diperlukan untuk mengidentifikasikan peluang dan ancaman dalam lingkungan perusahaan. Bila diterapkan dengan akurat pada perusahaan akan berimplikasi bagus bagi sebuah desain strategi yang telah dirancang. Hasil pengolahan data maka diperoleh lima kekuatan, kelemahan perusahaan serta lima peluang dan ancaman bagi PT.Imago Kreasi Komunika yang sangat berpengaruh pada perkembangan perusahaan.

\section{Kekuatan}

1. Memiliki divisi 'final artwork (FA) khusus packaging'.Final artwork kemasan bertujuan mendapatkan warna yang konsisten dan dapat diprediksi antara monitor dan hasil cetak berupa hasil cetakan atau digital color proof. Dengan adanya FA khusus kemasan, klien tidak perlu khawatir warna tidak sesuai. Karena warna yang diinginkan dapat dipastikan sesuai dengan harapan.

2. Memiliki track record baik sehingga terus mendapatkan kontrak kerja dengan perusahaan Fast Moving Consumer Goods (FMCG). terkemuka. Dipercaya oleh klien selama bertahun-tahun adalah hal yang sulit. Ini bukti kepercayaan klien atas kualitas dan servis perusahaan.

3. Memiliki account service senior, tim yang andal serta pimpinan yang dipercaya klien. Account service senior yang dipercaya oleh klien adalah aset yang amat berharga bagi perusahaan

4. Memiliki sertifikasi ISO 9001:2008 dari TUV Nord untuk sistem manajemen mutu sebagai jaminan kualitas produk dan jasa yang dihasilkan. Sebagai bukti kepada klien bahwa Imago serius dengan kualitas.

5. Perusahaan memiliki sedikit utang. Perusahaan dapat menyerap term of payment dari klien yang seringkali sampai tiga bulan.

\section{Kelemahan}

1. Proporsi pendapatan terlalu didominasi oleh sebuah klien/perusahaan. Pada awal perusahaan berdiri PT.Nestle Indonesia mendominasi sebagai klien terbesar PT. Imago. Hingga kini keadaan tersebut masih bertahan, meskipun demikian terdapat klien lain yang menjadi klien tetap perusahaan, yaitu Mondelez, PepsiCo Indonesia, Wyeth Indonesia.

2. Kurangnya modal dan tempat usaha untuk mengembangkan usaha. Karena perusahaan sepenuhnya menggunakanuang perusahaan dan tidak meminjam bank untuk melakukan operasionalnya maka modal yang dimiliki perusahaan terbatas untuk mengembanngkan perusahaan. Tempat usaha yang kurang besar dan terbatas juga menjadi kendala untuk menambah jumlah karyawan maupun mesin.

3. Kehilangan pegawai (marketing) di top level management yang kompeten dan merekrut pengganti yangtidakkompeten. Kehilangan pegawai PT. Imago 
Kreasi Komunika yang kompeten berpengaruh pada perkembangan perusahaan. Karyawan yang merasa strategy perusahaan tidak sesuai dengan strategi yang diinginkannya cenderung tidak bertahan lama di perusahaan tersebut (Da Silva et al. 2010).

4. Sebagian besar karyawan berada di comfort zone dan tidak menaati peraturan perusahaan dari jajaran top level hingga low level serta shareholder yang juga berperan sebagai pegawai menimbulkan conflict of interest tersendiri yang memengaruhi kebijakan perusahaan.

5. Tingginya biaya operasional perusahaan (cost) sehingga menurunkan revenue perusahaan. Banyak pegawai lama yang membutuhkan biaya cukup besar dan kebijakan untuk merekrut orang baru dengan pengalaman membuat biaya untuk gaji sangat besar.

Selanjutnya, matrik IFAS PT. Imago Kreasi Komunika selengkapnya pada Tabel 4.

\section{Analisis Faktor Eksternal}

Hasil analisis eksternal dengan melakukan analisis lingkungan (natural environment) dan sosial (societal environmental) dikumpulkan dalam suatu daftar faktorfaktor strategik eksternal. Faktor-faktor strategik eksternal yang penting dan berpotensi memengaruhi perusahaan berjumlah 10 faktor yang tergolong peluang sebanyak lima faktor dan ancaman sebanyak lima faktor.

\section{Peluang}

1. Produk kosmetik, farmasi dan elektronik belum membuat end-to-end design packaging secara khusus. Belum banyak perusahaan yang dapat melakukan hal seperti ini di industri periklanan yang mengkhususkan bisnis ini.

Tabel 4. Matrik IFAS PT. Imago Kreasi Komunika

\begin{tabular}{|c|c|c|c|c|}
\hline Internal strategic faktors & Weight & $\begin{array}{c}\text { Rating } \\
(1-5)\end{array}$ & $\begin{array}{l}\text { Weighted } \\
\text { score }\end{array}$ & Respon \\
\hline \multicolumn{5}{|l|}{ Kekuatan } \\
\hline $\begin{array}{l}\text { Memiliki divisi 'final artwork khusus } \\
\text { packaging' }\end{array}$ & 0,11 & 4,00 & 0,43 & $\begin{array}{l}\text { Kekuatan ini harus diubah menjadi } \\
\text { keunggulan kompetitif perusahaan }\end{array}$ \\
\hline $\begin{array}{l}\text { Memiliki track record baik sehingga terus } \\
\text { mendapatkan kontrak kerja dengan perusahaan } \\
\text { FMCG terkemuka }\end{array}$ & 0,11 & 3,71 & 0,41 & Terus meningkatkan kualitas \\
\hline $\begin{array}{l}\text { Memiliki account service senior, tim yang } \\
\text { andal serta pimpinan yang dipercaya klien }\end{array}$ & 0,12 & 3,71 & 0,44 & $\begin{array}{l}\text { Memberikan profit sharing } \\
\text { perusahaan agar karyawan tersebut } \\
\text { loyal }\end{array}$ \\
\hline $\begin{array}{l}\text { Memiliki sertifikasi ISO 9001:2008 dari TUV } \\
\text { Nord untuk sistem manajemen mutu }\end{array}$ & 0,08 & 3,50 & 0,28 & $\begin{array}{l}\text { Mempertahankan sertifikasi ini agar } \\
\text { ISO 9001:2008 dari TUV Nord dapat } \\
\text { terus diperpanjang }\end{array}$ \\
\hline Perusahaan memiliki sedikit utang & 0,09 & 3,57 & 0,31 & Pertahankan dan mulai berinvestasi \\
\hline \multicolumn{5}{|l|}{ Kelemahan } \\
\hline $\begin{array}{l}\text { Proporsi pendapatan terlalu didominasi oleh } \\
\text { sebuah klien/perusahaan }\end{array}$ & 0,09 & 3,71 & 0,34 & $\begin{array}{l}\text { Meningkatkan porsi pemasukan di } \\
\text { luar klien utama }\end{array}$ \\
\hline $\begin{array}{l}\text { Kurangnya modal dan tempat usaha untuk } \\
\text { mengembangkan usaha }\end{array}$ & 0,09 & 3,21 & 0,30 & $\begin{array}{l}\text { Pengelolaan cash flow dan } \\
\text { mengembangkan sarana dan prasarana } \\
\text { untuk perkembangan usaha. }\end{array}$ \\
\hline $\begin{array}{l}\text { Kehilangan pegawai (marketing) di top level } \\
\text { management yang kompeten dan merekrut } \\
\text { pengganti yang tidak kompeten }\end{array}$ & 0,10 & 3,36 & 0,34 & $\begin{array}{l}\text { Mengadakan job values evaluation } \\
\text { untuk pegawai dan mengembangkan } \\
\text { knowledge management }\end{array}$ \\
\hline $\begin{array}{l}\text { Sebagian besar karyawan berada di comfort } \\
\text { zone dan tidak mentaati peraturan perusahaan } \\
\text { dari jajaran top level hingga low level } \\
\text { perusahaan. }\end{array}$ & 0,11 & 3,79 & 0,40 & $\begin{array}{l}\text { Perlu dilakukan evaluasi struktur yang } \\
\text { ada agar dihasilkan struktur yang } \\
\text { lebih efektif }\end{array}$ \\
\hline \multirow[t]{2}{*}{ Tingginya biaya operasional perusahaan (cost) } & 0,10 & 3,57 & 0,37 & Melakukan strategic cost reduction \\
\hline & 1,00 & & 3,50 & \\
\hline
\end{tabular}


2. Beriklan adalah sarana perusahaan untuk mempromosikan produk (ATL dan BTL). Banyaknya perusahaan di Indonesia membuka peluang bagi perusahaan iklan di Indonesia terus berkembang. Menurut data $\mathrm{PwC}$, perkembangan iklan di Indonesia terus berkembang hingga tahun 2018.

3. Banyak event pemerintah dengan nilai diatas tiga milyar. Kantor-kantor pemerintahan di Indonesia memiliki banyak kegiatan event, dan sejumlah event berskala besar hingga mencapai diatas tiga milyar. Untuk itu perusahaan yang ingin turut serta terlibat menyelenggarakan event harus memiliki modal dasar sesuai ketentuan yang ditentukan pemerintah.

4. Adanya teknologi final artwork packaging dengan ISO 12647 (khusus color management) dari Jerman. Peluang mengembangkan business unit final artwork packaging sangat besar. Masih banyak perusahaan consumer goods dan percetakan yang belum mengenal pentingnya color management.

5. 3D printing mulai yang berkembang di Indonesia.

\section{Ancaman}

1. Agency lain menawarkan desain lebih bagus dan menarik. Perusahaan-perusahaan banyak menggunakan agency kecil karena desain yang diberikan masih segar dengan tenaga-tenaga baru yang sangat kreatif.

2. Agency lain memberikan harga lebih kompetitif. Keadaaan ekonomi yang tidak stabil saat ini banyak menyebabkan perusahaan memilih agency dengan harga yang lebih kompetitif, terutama dalam situasi untuk mengurangi pengeluaran perusahaan yang bersifat promosi.

3. Tingginya harga bahan baku (tinta, kertas,dll) akibat lemahnya rupiah. Keadaan ekonomi nasional menjadi faktor utama tingginya harga bahan baku.

4. Masuknya agency asing dengan lebih leluasa ke Indonesia dengan diterapkan MEA (Masyarakat Ekonomi ASEAN). Diterapkannya MEA (Masyarakat Ekonomi ASEAN) secara tidak langsung merupakan ancaman bagi tenaga kerja di Indonesia, tidak terlepas juga perusahaan iklan. Agency asing juga dapat masuk dengan lebih leluasa dengan menawarkan kreativitas menarik dan harga sama atau mungkin lebih murah.

5. Ketidakpastian kondisi politik di Indonesia yang memengaruhi ekonomi nasional sehingga banyak perusahaan mengurangi belanja iklan.
Selanjutnya, matrik External Factor Analysis Summary (EFAS) PT Imago Kreasi Komunika selengkapnya pada Tabel 5.

\section{Formulasi Strategi Bagi PT. Imago Kreasi Komunika}

Hasil evaluasi IFAS dan EFAS faktor-faktor yang paling berpengaruh dipilih sepuluh faktor yang memiliki nilai terbobot tertinggi untuk dimasukkan ke dalam SFAS sehingga memperoleh formulasi strategi. Penyusunan SFAS dilakukan dengan memilih 4-5 faktor internal dan eksternal yang memiliki bobot lebih tinggi dibandingkan dengan faktor lain. Pada tabel SFAS ditentukan tingkat urgency atau durasi waktu untuk mengatasi permasalahan faktor-faktor tersebut. Hasil perhitungan maka dipilih faktor strategik yang memiliki skor terbobot $\geq 0,3$. Skor 5 menunjukkan respon sangat baik, sebaliknya bila 1 maka respon perusahaan sangat buruk. Durasi untuk pendek (short) kurang dari 1 tahun, menengah (intermediate) yaitu 1-3 tahun, dan panjang (long) yakni lebih dari tiga tahun.

Hasil dari analisis ini adalah sebuah formulasi strategi. Dalam proses sebuah perencanaan strategi, formulasi strategi merupakan 'black box' sebuah perencanaan strategi. Disinilah proses berpikir dan alat yang digunakan diolah untuk membuat perencanaan strategi (Boyd et al. 2001). Penelitian dengan mengidentifikasi faktor-faktor yang memengaruhi perusahaan dalam menjalankan bisnisnya baik faktor internal maupun eksternal merupakan faktor-faktor penting yang memengaruhi perusahaan dalam menjalankan bisnisnya dan dapat menghasilkan alternative strategi (Mitrady et al. 2015). Karakteristik berpikir strategik yang memengaruhi sebuah formulasi strategi dan performa bisnis, yaitu kemampuan berpikir konseptual, berpikir visioner, kemampuan berpikir secara analitis, kemampuan mensintesa, objektif, kreatif dan kemampuanbelajar(Nuntamanopetal. 2013).Penelitian yang dilakukan terhadap PT.Imago Kreasi Komunika mengolah dengan menggunakan matriks SFAS yang tidak sama dengan pengolahan yang dilakukan oleh Mitrady. Namun, keduanya memiliki kesamaan, yaitu mengidentifikasikan faktor-faktor internal dan eksternal yang memengaruhi perusahaan. Dari hasil penelitian terhadap PT. Imago Kreasi Komunika diidentifikasikan sepuluh faktor yang memengaruhi perusahaan secara internal dan eksternal seperti dipaparkan pada Tabel 6. 
Nilai keseluruhan dari analisis faktor strategik adalah 3,52 yang menunjukkan bahwa perusahaan responsif terhadap perubahan yang terjadi dan masih dapat tumbuh melalui formulasi strategi yang tepat. Terbobot tertinggi pertama dengan skor 0,41 adalah memiliki account service senior, tim yang handal serta pimpinan yang dipercaya klien. Bila dilihat dari uraian tersebut perusahaan mampu bertahan dan mempertahankan klien hingga lebih dari tigabelas tahun tidak terlepas dari kinerja yang telah dilakukan account service senior selama ini. Oleh karena itu, perusahaan sebaiknya memberi kesempatan karyawan yang kompeten dan menghasilkan pemasukan besar bagi perusahaan untuk mendapatkan profit sharing perusahaan agar karyawan tersebut loyal.

Terbobot tertinggi berikutnya adalah perusahaan memiliki divisi 'final artwork khusus packaging' sebesar 0,40. Dalam kurun waktu kurang dari satu tahun PT.Imago Kreasi Komunika harus dapat menjadikan kompetensi ini menjadi keunggulan kompetitif (competitive advantage). Divisi ini dapat berkembang dengan baik karena sebuah penelitian menunjukkan bahwa bentuk design sebuah kemasan memengaruhi daya beli konsumen untuk membeli produk (Cahyorini dan Rusfian, 2011).

Tabel 5. Matrik EFAS PT. Imago Kreasi Komunika

\begin{tabular}{|c|c|c|c|c|}
\hline Internal strategic faktors & Weight & $\begin{array}{c}\text { Rating } \\
(1-5)\end{array}$ & $\begin{array}{l}\text { Weighted } \\
\text { score }\end{array}$ & Respon \\
\hline \multicolumn{5}{|l|}{ Peluang } \\
\hline $\begin{array}{l}\text { Produk kosmetik, farmasi dan elektronik belum } \\
\text { membuat end-to-end design packaging secara } \\
\text { khusus }\end{array}$ & 0,09 & 3,36 & 0,31 & $\begin{array}{l}\text { Peluang untuk mendapatkan klien } \\
\text { di bidang kosmetik, farmasi dan } \\
\text { elektronik }\end{array}$ \\
\hline $\begin{array}{l}\text { Beriklan adalah sarana perusahaan untuk } \\
\text { produk (ATL dan BTL) }\end{array}$ & 0,11 & 3,00 & 0,34 & $\begin{array}{l}\text { Peluang untuk mendapatkan iklan } \\
\text { ATL dan BTL masih sangat besar }\end{array}$ \\
\hline $\begin{array}{l}\text { Banyak event pemerintah dengan nilai di atas } \\
\text { tiga milyar }\end{array}$ & 0,09 & 3,71 & 0,35 & $\begin{array}{l}\text { Meningkatkan modal dasar } \\
\text { untuk dapat mengambil peluang } \\
\text { mengerjakan proyek pemerintah }\end{array}$ \\
\hline $\begin{array}{l}\text { Adanya teknologi Final Artwork Packaging } \\
\text { dengan ISO } 12647 \text { (khusus color management) } \\
\text { dari Jerman }\end{array}$ & 0,11 & 3,36 & 0,38 & $\begin{array}{l}\text { Perusahaan harus menyiapkan } \\
\text { investasi yang cukup mahal untuk } \\
\text { mendapatkan ISO } 12647 \text {. }\end{array}$ \\
\hline $\begin{array}{l}\text { 3D printing mulai yang berkembang di } \\
\text { Indonesia }\end{array}$ & 0,09 & 2,86 & 0,26 & $\begin{array}{l}\text { Mengambil peluang ini dengan } \\
\text { merekrut ahli di bidang 3D digital } \\
\text { printing dan investasi mesin }\end{array}$ \\
\hline \multicolumn{5}{|l|}{ Ancaman } \\
\hline $\begin{array}{l}\text { Agency lain menawarkan design lebih bagus } \\
\text { dan menarik }\end{array}$ & 0,11 & 3,50 & 0,37 & $\begin{array}{l}\text { Memberikan pelayanan yang } \\
\text { komprehensif seperti one stop } \\
\text { solution berkenaan dengan design. }\end{array}$ \\
\hline Agency lain memberikan harga lebih kompetitif & 0,11 & 3,29 & 0,37 & $\begin{array}{l}\text { Beralihnya klien ke agency lain harus } \\
\text { segera diatasi dengan memberikan } \\
\text { diskon atau package price oleh } \\
\text { perusahaan }\end{array}$ \\
\hline $\begin{array}{l}\text { Tingginya harga bahan baku (tinta, kertas, dll) } \\
\text { akibat lemahnya rupiah }\end{array}$ & 0,09 & 3,21 & 0,30 & $\begin{array}{l}\text { Melakukan strategi cost reduction, } \\
\text { mengikat kontrak harga dengan } \\
\text { supplier agar tidak terpengaruh } \\
\text { kenaikan harga }\end{array}$ \\
\hline $\begin{array}{l}\text { Masuknya Agency asing dengan lebih leluasa } \\
\text { ke Indonesia dengan diterapkan MEA } \\
\text { (Masyarakat Ekonomi ASEAN) }\end{array}$ & 0,08 & 3,00 & 0,24 & $\begin{array}{l}\text { Menyiapkan SDM yang tangguh } \\
\text { dan memiliki competitive advantage } \\
\text { untuk bersaing }\end{array}$ \\
\hline $\begin{array}{l}\text { Ketidakpastian kondisi politik di Indonesia } \\
\text { yang memengaruhi ekonomi nasional sehingga } \\
\text { perusahaan mengurangi belanja iklan }\end{array}$ & 0,10 & 3,14 & 0,32 & $\begin{array}{l}\text { Harus mulai mencari sumber } \\
\text { pendapatan lain untuk mengantisipasi } \\
\text { keadaan ini }\end{array}$ \\
\hline Total & 1,00 & & 3,47 & \\
\hline
\end{tabular}


Tabel 6. Strategic SFA PT.Imago Kreasi Komunika

\begin{tabular}{|c|c|c|c|c|c|c|c|}
\hline \multirow{2}{*}{ Strategic factors } & \multirow{2}{*}{ Weight } & \multirow{2}{*}{ Rating } & \multirow{2}{*}{$\begin{array}{l}\text { Weighted } \\
\text { Skor }\end{array}$} & \multicolumn{3}{|c|}{ Duration } & \multirow{2}{*}{ Respons } \\
\hline & & & & Short & mediate & Long & \\
\hline $\begin{array}{l}\text { Memiliki divisi 'final } \\
\text { artwork khusus } \\
\text { packaging' }\end{array}$ & 0,10 & 4,00 & 0,40 & $\mathrm{X}$ & & & $\begin{array}{l}\text { Kekuatan ini harus diubah } \\
\text { menjadi keunggulan kompetitif } \\
\text { perusahaan. }\end{array}$ \\
\hline $\begin{array}{l}\text { Memiliki track record } \\
\text { baik }\end{array}$ & 0,10 & 3,71 & 0,37 & $\mathrm{X}$ & $\mathrm{X}$ & $\mathrm{X}$ & $\begin{array}{l}\text { Meningkatkan kualitas SDM } \\
\text { sesuai bidang masing-masing, } \\
\text { meninngkatkan investasi }\end{array}$ \\
\hline $\begin{array}{l}\text { Memiliki account } \\
\text { service senior, tim } \\
\text { handal dan pimpinan } \\
\text { yang dipercaya klien }\end{array}$ & 0,11 & 3,71 & 0,41 & & $\mathrm{X}$ & $\mathrm{X}$ & $\begin{array}{l}\text { Memberikan kesempatan } \\
\text { karyawan yang kompeten dan } \\
\text { menghasilkan pemasukan } \\
\text { besar bagi perusahaan untuk } \\
\text { mendapatkan profit sharing } \\
\text { perusahaan agar karyawan } \\
\text { tersebut loyal. }\end{array}$ \\
\hline $\begin{array}{l}\text { Sebagian karyawan } \\
\text { berada di comfort zone } \\
\text { dan tidak mentaati } \\
\text { peraturan perusahaan }\end{array}$ & 0,10 & 3,79 & 0,38 & $\mathrm{X}$ & & & $\begin{array}{l}\text { Evaluasi struktur yang ada } \\
\text { agar dihasilkan struktur yang } \\
\text { lebih efektif }\end{array}$ \\
\hline $\begin{array}{l}\text { Tingginya biaya } \\
\text { operasional } \\
\text { perusahaan }(\cos t)\end{array}$ & 0,09 & 3,57 & 0,32 & $\mathrm{X}$ & & & $\begin{array}{l}\text { Melakukan strategic cost } \\
\text { reduction. }\end{array}$ \\
\hline $\begin{array}{l}\text { Produk kosmetik, } \\
\text { farmasi dan elektronik } \\
\text { belum membuat } \\
\text { end-to-end design } \\
\text { packaging khusus. }\end{array}$ & 0,10 & 3,00 & 0,30 & $\mathrm{X}$ & $\mathrm{X}$ & & $\begin{array}{l}\text { Mendapatkan klien baru di } \\
\text { bidang kosmetik, farmasi, } \\
\text { elektronik dan otomotif }\end{array}$ \\
\hline $\begin{array}{l}\text { Adanya teknologi final } \\
\text { artwork packaging } \\
\text { dengan ISO } 12647 \\
\text { (khusus color } \\
\text { management) dari } \\
\text { Jerman. }\end{array}$ & 0,10 & 3,36 & 0,34 & $\mathrm{X}$ & $\mathrm{X}$ & & $\begin{array}{l}\text { SDM perusahaan siap untuk } \\
\text { mendapatkan ISO } 12647 \text {, } \\
\text { tetapi harus mempelajari lebih } \\
\text { dalam lagi. }\end{array}$ \\
\hline $\begin{array}{l}\text { Agency lain } \\
\text { menawarkan design } \\
\text { lebih bagus dan } \\
\text { menarik. }\end{array}$ & 0,10 & 3,50 & 0,35 & $\mathrm{X}$ & & & $\begin{array}{l}\text { SDM perlu dibekali dengan } \\
\text { tambahan ilmu agar dapat } \\
\text { bersaing. Merekrut head } \\
\text { designer yang kompeten. } \\
\text { Memberikan pelayanan } \\
\text { komprehensif seperti one stop } \\
\text { solution berkenaan dengan } \\
\text { design. }\end{array}$ \\
\hline $\begin{array}{l}\text { Agency lain } \\
\text { memberikan harga } \\
\text { lebih kompetitif }\end{array}$ & 0,10 & 3,29 & 0,33 & $\mathrm{X}$ & & & $\begin{array}{l}\text { memberikan diskon atau } \\
\text { package price oleh perusahaan }\end{array}$ \\
\hline $\begin{array}{l}\text { Ketidakpastian kondisi } \\
\text { politik di Indonesia } \\
\text { sehingga perusahaan } \\
\text { mengurangi belanja } \\
\text { iklan }\end{array}$ & 0,10 & 3,14 & 0,32 & $\mathrm{X}$ & $\mathrm{X}$ & $\mathrm{X}$ & $\begin{array}{l}\text { Mempersiapkan dana } \\
\text { cadangan seandainya semua } \\
\text { kegiatan berkurang karena } \\
\text { krisis. }\end{array}$ \\
\hline Total & 1,00 & & 3,52 & & & & \\
\hline
\end{tabular}


Terbobot tertinggi ketiga senilai 0,38 adalah sebagian karyawan berada di comfort zone dan tidak mentaati peraturan perusahaan dari jajaran top level hingga low level. Permasalahan yang terjadi di badan perusahaan ini harus segera diatasi dengan tingkat urgency tinggi. Kurang dari setahun perusahaan harus segera mengatasi permasalahan ini, karena bila hal ini dibiarkan berlarutlarut maka perusahaan dapat merugi.

Untuk tiga nilai terbobot paling rendah pada matriks SFAS, yaitu banyak peluang beriklan adalah sarana perusahaan untuk mempromosikan produk (ATL dan BTL) 0,30. Dari hasil analisis ditemukan bahwa, meskipun peluang untuk mendapatkan klien baru sangat terbuka lebar, namun perusahaan tetap terfokus pada klien yang ada saat ini, yaitu perusahaan FMCG.

Faktor dengan terbobot terendah berikutnya dengan nilai 0,32 adalah ketidakpastian kondisi politik di Indonesia yang memengaruhi ekonomi nasional sehingga perusahaan mengurangi belanja iklan. Hal ini tidak berdampak langsung dan sporadis, namun secara perlahan-lahan. Seberapa besar faktor ini memengaruhi perusahaan dapat dilihat melalui perubahan beberapa pekerjaan. Misalnya FMCG yang semula memberikan pekerjaan communication programme menyeluruh selama setahun, kemudian mengurangi aktivitasnya menjadi hanya berupa beberapa event kecil.

Dan yang terakhir adalah terbobot paling rendah ketiga pada matriks SFAS sebesar 0,32 adalah tingginya biaya operasional perusahaan (cost) sehingga menurunkan revenue perusahaan. Dalam hal ini perusahaan perlu melakukan strategic cost reduction. Perusahaan harus mulai melakukan evaluasi terhadap biaya-biaya dan faktor penyebab tingginya biaya. Komponen yang paling berpengaruh dari biaya operasional adalah gaji karyawan. Beberapa karyawan perlu dievaluasi ulang dengan menghentikan karyawan kontrak yang tidak mendatangkan profit bagi perusahaan. Evaluasi terhadap biaya-biaya entertainment yang tidak perlu juga patut menjadi perhatian perusahaan.

\section{Implikasi Manajerial}

Hasil analisis formulasi strategi memaparkan kekuatan, kelemahan, peluang dan ancaman serta rencana yang akan dilakukan perusahaan lima tahun mendatang. Informasi yang dipaparkan akan menjadi rekomendasi bagi perusahaan untuk merumuskan strategi dalam pengembangan perusahaan dan bersaing dalam bisnis. Berdasarakan analisis yang dilakukan maka perlu diadakan kick off meeting bagi top level management untuk mengevaluasi dan mematangkan perencanaan strategi untuk lima tahun ke depan karena PT.Imago Kreasi Komunika memiliki Unique Selling Point (USP) yang tidak dimiliki oleh perusahaan iklan lain, yaitu final artwork packaging design yang dapat dikembangkan lebih luas lagi tidak hanya mencakup kemasan. Namun, dapat dikembangkan menjadi 4D prototyping.

\section{KESIMPULAN DAN SARAN}

\section{Kesimpulan}

Hasil pembahasan dan analisis yang telah dilakukan terhadap seluruh aspek dalam membuat suatu perencanaan strategik sesuai dengan tujuan penelitian. Strategi utama perusahaan untuk dapat bersaing dengan perusahaan iklan lain di Indonesia adalah dengan mengembangkan USP yang tidak dimiliki perusahaan iklan lain, yaitu divisi 'final artwork khusus kemasan'. Dalam waktu kurang dari satu tahun PT.Imago Kreasi Komunika harus dapat menjadikan kompetensi ini menjadi keunggulan kompetitif (competitive advantage).

Hasil analisis faktor internal PT.Imago Kreasi Komunika menunjukkan beberapa kekuatan yang dapat menjadi kompetensi inti, yaitu FA khusus kemasan menggunakan sistem color management. Sebaliknya, hasil analisis eksternal PT.Imago Kreasi Komunika menunjukkan bahwa perusahaan memiliki peluang besar mengembangkan end-to-end design packaging untuk perusahaan multinasional selain FMCG seperti kosmetik, pelumas dan berbagai kemasan yang belum tersentuh perusahaan. Namun, PT.Imago juga harus siap menghadapi masuknya perusahaan iklan maupun tenaga asing dengan diberlakukannya MEA di tahun 2016.

\section{Saran}

Identifikasi formulasi strategi yang diperoleh dapat digunakan untuk membuat perencanaan strategik PT.Imago Kreasi Komunika dengan lebih tepat untuk lima tahun ke depan. Melalui perencanaan strategik dapat disusun program dan implementasi bagi PT.Imago 
Kreasi Komunika. Dengan perencanaan strategik yang tepat, perusahaan dapat tumbuh dan berkembang sehingga perusahaan dapat bersaing.

Penelitian mengenai formulasi strategi perusahaan iklan masih sangat jarang ditemukan terutama di Indonesia. Pada penelitian berikutnya, mennganalisis beberapa perusahaan iklan di Indonesia dan menganalisis faktor keberhasilan formulasi strategi yang diterapkan pada perusahaan iklan di Indonesia dapat menjadi studi yang menarik untuk diteliti lebih lanjut.

\section{DAFTAR PUSTAKA}

Azaddin SK. 2012. Mission, purpose, and ambition: Redefining the mission statement. Journal of Strategy and Management 5(3):236-251. https:// doi.org/10.1108/17554251211247553.

AC Nielson. 2015. Belanja Iklan Naik 6\% di Kuartal kedua Tahun 2015. http://www.nielsen.com/id/ en/press-room/2015/Belanja-Iklan-Naik-6-\% -di-Kuartal-Kedua-2015.html 28 Oktober 2015.

Boyd L, Gupta M, Sussman L. 2001. A new approach to strategy formulation: Opening the black box. Journal of Education for Business 76(6):338-344. https://doi.org/10.1080/08832320109599659.

Cahyorini A, Rusfian EZ. 2011. The effect of packaging design on impulsive buying. Journal of Administrative Science \& Organization, January 2011, Page 11-12.

Cocks G. 2010. Emerging concepts for implementing strategy. TQM Journal 22(3): 260-266. https:// doi.org/10.1108/17542731011035505.

De Gregorio F, Cheong Y, Kim K. 2012. Intraorganizational conflict within advertising agencies: antecedents and outcomes. Journal of Advertising 41(3):19-34.

Da Silva N, Hutcheson J, Wahl GD. 2010. Organizational strategy and employee outcomes: A person-organization fit perspective. The Journal of Psychology 144(2):145-61. https:// doi.org/10.1080/00223980903472185.
King DL, Case CJ, Premo KM. 2010. Current mission statement emphasis: be ethical and go global. Academy of Strategic Management Journal, 9(2):71-87.

PT.Imago. 2015. Laporan Rugi Laba PT.Imago Kreasi Komunika Tahun 2010-2014. Jakarta: PT.Imago Kreasi Komunika.

Mazzarol T, Reboud S, Soutar GN. 2009. Strategic planning in growth oriented small firms. International Journal of Entrepreneurial Behaviour \& Research 15(4): 320-345. https:// doi.org/10.1108/13552550910967912.

Mitrady I, Daryanto HK, Maulana A. 2015. Loan distribution strategy PT. Bank X (Persero), Tbk-Bogor credit business unit. Jurnal Aplikasi Bisnis dan Manajemen 1(2): 98-107. https://doi. org/10.17358/JABM.1.2.98.

Nuntamanop P, Kauranen I, Igel B. 2013. A new model of strategic thinking competency. Journal of Strategy and Management 6(3):242-264. https:// doi.org/10.1108/JSMA-10-2012-0052.

Powers EL. 2012. Organizational mission statement guidelines revisited. International Journal of Management \& Information Systems 16(4):281. https://doi.org/10.19030/ijmis.v16i4.7304.

Tantra D, Kendengis Y, Santoso LW. 2015. Perencanaan strategis sistem informasi pada perusahaan jasa ekspedisi PT. X. Jurnal Infra 3(1):188.

Wheelen T, Hunger D. 2012. Strategic Management and Business Policy 13th ed. New Jersey: Pearson.

Widodo. 2011. Building strategy quality. International Journal of Business and Management 6(8): 180 192. https://doi.org/10.5539/ijbm.v6n8p180.

Widodo AE, Djohar S, Sanim B. 2008. Arsitektur strategik PT.Sigma Utama Berbasis kompetensi inti. National Conference on Management Research 2008

Zuhaidha SA, Santoso S, Maesaroh M. 2014. Perencanaan strategi pengembangan ruang terbuka hijau Kota Semarang (studi kasus: Hutan Wisata Tinjomoyo). Journal of Public Policy and Management Review 3(2): 390-399. 